\title{
A Adição e Subtração no Modo de Ensino Davydoviano
}

\section{The addition and subtractionin the Davydovian teaching mode}

\author{
Ester de Souza Bitencourt Alves* \\ ORCID iD 0000-0002-8914-6940 \\ Ademir Damazio** \\ ORCID iD 0000-0002-6755-3377
}

\begin{abstract}
Resumo
A presente investigação analisa tarefas particulares de estudo, pertinentes ao modo de organização de ensino desenvolvido por Davýdov e colaboradores, cuja finalidade é o desenvolvimento do pensamento teórico dos estudantes. A delimitação se volta à apreensão dos componentes do sistema conceitual de adição e subtração, referentes ao primeiro ano escolar. A análise, com base na Teoria Histórico-Cultural, centra-se no movimento de permanência e de surgimento de componentes essenciais dos conceitos, proporcionados pelas tarefas, que foram extraídas de dois livros: didático e orientação ao professor. As tarefas proporcionam um movimento de ida e volta, que cria a necessidade de determinar ou eliminar a desigualdade entre grandezas, que constituem propriedades da adição e subtração, respectivamente. Geram apropriações das significações algébrica, aritmética e geométrica.
\end{abstract}

Palavras-chave: Ensino. Sistema Conceitual de Adição/Subtração. Movimento de Permanência e Surgimento. Relação Todo-Partes.

\begin{abstract}
The present research analyzes particular study tasks, pertinent to the way of teaching organization, developed by Davýdov and collaborators, whose purpose is the students' theoretical thinking development. The delimitation turns to the apprehension of the addition and subtraction conceptual systems' components, referring to the first school year. The analysis, based on the Historical-Cultural Theory, focuses on the movement of permanence and the emergence of the concepts' essential components, provided by the tasks, which were extracted from two books: didactic (book) and teacher orientation (book). Tasks provide a round-trip, which creates the need to determine or eliminate the inequality between magnitudes, which are addition and subtraction properties, respectively. They generate appropriations of algebraic, arithmetic, and geometric meanings.
\end{abstract}

Keywords: Teaching. Conceptual System Addition/Subtraction. Movement of Permanence and Appearance. AllParts Relation.

\footnotetext{
* Mestre em Educação. Programa de Pós-Graduação em Educação da Universidade do Extremo Sul Catarinense (UNESC). Professora de Rede Pública Estadual, Criciúma, Santa Catarina, Brasil. Endereço para correspondência: Rua Constantino Zanette, 250, casa, Quarta Linha, Criciúma, Santa Catarina, Brasil, CEP: 88812-381.E-mail: esterr_alvess@ @otmail.com.

** Doutor em Educação. Universidade Federal de Santa Catarina (UFSC). Professor do Programa de PósGraduação em Educação da Universidade do Extremo Sul Catarinense (UNESC), Criciúma, Santa Catarina, Brasil. Endereço para correspondência: Avenida Universitária, 1105, Bloco P - Sala 30, Bairro Universitário, Criciúma, Santa Catarina, Brasil, CEP: 88.806-000.E-mail: add@unesc. net
} 


\section{Introdução}

O presente estudo tem como referência um modo de organização de ensino da Matemática que se configura entre os sistemas de ensino vigentes na Rússia e em outros países. Tem como precursor Vasili Vasilievich Davýdov ${ }^{1}$, que foi membro da Academia de Ciências Pedagógicas da Rússia, doutor em Psicologia e professor universitário. Pertence à terceira geração de psicólogos soviéticos e seguidor da Teoria Histórico-Cultural de Vigotsky (LIBÂNEO, 2004). Dedicou-se ao aprofundamento dos estudos vigotskyanos referentes ao desenvolvimento cognitivo. Em decorrência, constituiu um grupo de colaboradores para a elaboração e a submissão à investigação de uma proposta para o ensino de Matemática que propiciasse a formação do pensamento teórico nos estudantes.

A proposta davydoviana se orienta pelos pressupostos da Teoria Histórico-Cultural e, por consequência, pela sua matriz, o materialismo histórico e dialético. Portanto, “[...] reflete os princípios do pensamento dialético [...]" (SOUZA, 2013, p. 55). Segundo Triviños (1995, p. 51), “[...] o materialismo dialético é a base filosófica do marxismo e como tal realiza a tentativa de buscar explicações coerentes, lógicas e racionais para os fenômenos da natureza, da sociedade e do pensamento". É nesse contexto teórico que Davídov (1988) expõe seu entendimento referente à finalidade da educação escolar:

\section{[...] formar nas crianças representações materialistas firmes, para produzir nelas o pensamento independente e melhorar significativamente a formação artística e estética; elevar o nível ideológico e teórico do processo de ensino e educação; expor com precisão os principais conceitos e as ideias básicas das disciplinas escolares; erradicar quaisquer manifestações de formalismo no conteúdo e métodos de ensino e no trabalho de formação e aplicar amplamente as formas e métodos ativos de ensino, etc. (DAVÍDOV, 1988, p. 170-171).}

Para atingir o propósito de levar os estudantes ao desenvolvimento do pensamento e da generalização teórica, Davýdov (1982) não só advoga, como também elabora e investiga uma nova organização do ensino, radicalmente distinta daquelas presentes nos sistemas educativos formais de seu tempo. Conforme Rosa (2012, p. 37), "Davydov dá ênfase ao papel da educação e do desenvolvimento intelectual do homem. Por isso, assim como os demais psicólogos/educadores russos, atribui como objeto da Psicologia a atividade”. Isso significa que o indivíduo humano se caracteriza como um ser em atividade. Em outras palavras, o desenvolvimento intelectual da personalidade e da consciência é marcado por distintas atividades que indicam o lugar que o ser humano ocupa na sociedade.

\footnotetext{
${ }^{1}$ As grafias Davýdov, Davydov, Davídov e Davidov se referem ao mesmo autor. Cada qual aparece no texto, conforme a obra citada.
} 
Davídov (1988), com base em Leontiev e Elkonin, destaca as três principais atividades indicadoras dos estágios do desenvolvimento humano: o jogo, na infância pré-escolar; o estudo, no período coincidente com a presença obrigatória do estudante na escola; e o trabalho, na idade adulta, em que somos inseridos no exercício profissional.

É nesse âmbito que definimos o problema de pesquisa: Quais as peculiaridades do modo de organização do ensino davydoviano para o sistema conceitual de adição e subtração? Para tanto, analisaremos três tarefas trazidas pelos livros didáticos e de orientação aos professores, que se voltam ao ensino e à aprendizagem dos conceitos matemáticos, a seguir nomeados, elaborados por Davýdov e sua equipe de colaboradores: 1) O livro didático dos alunos do primeiro ano: Математика: Учебник для 2 класса начальной школы - Livro didático e de exercícios para os estudantes da primeira série. 2) O livro de orientação ao professor: Обучение математике. 1 класс: Пособие для учителей начальной школы ${ }^{2}-$ Ensino de Matemática. $1^{\circ}$ ano: livro do professor do ensino fundamental.

A delimitação para a análise de apenas três tarefas ocorre por considerarmos que elas traduzem a ideia do movimento complexo de idas e voltas, que acenam para as peculiaridades de cada uma delas, no âmbito da universalidade do sistema conceitual de adição e subtração, bem como da essência do conceito: a relação todo-partes (ROSA, 2012); (ROSA; DAMAZIO; ALVES, 2013).

Nesse sentido, a primeira tarefa trata da ideia comparativa aditiva que consiste em determinar a diferença entre dois objetos, por meio de representações objetal e gráfica (segmento de reta). A segunda estabelece a ideia comparativa subtrativa que consiste em eliminar a diferença entre dois objetos, por meio de representações objetal e gráfica (segmento de reta). E a terceira abrange a unificação da ideia comparativa aditiva e subtrativa num único objeto, por meio de representações objetal e gráfica (segmento de reta).

O foco está no movimento do que é considerado essencial no processo de apropriação, por parte dos estudantes, do referido sistema conceitual. Isso gera a necessidade de estar atento às ideias centrais das tarefas particulares a serem desenvolvidas pelos estudantes. Para tal finalidade, a referência são os livros didáticos e as correspondentes orientações propostas aos professores para a condução dos estudantes na resolução das tarefas. O movimento da análise se caracteriza pelo que emerge nas tarefas como essencial do sistema de conceito, sua permanência e superação no decorrer do primeiro ano do Ensino Fundamental.

\footnotetext{
${ }^{2}$ A tradução desses livros, da língua russa para o Português, foi de Elvira Kim, professora da Universidade Federal do Paraná.
} 


\section{Fundamentos da proposição davydoviana}

Davýdov, em suas obras - e vale destacar Davýdov (1982) -, voltou-se para a proposição e para a investigação da organização do ensino que levassem as crianças a desenvolverem a atividade de estudo. Davídov e Slobódchikov (1991) partem do pressuposto de que escola e sociedade constituem uma unidade. Ou seja, há um reflexo mútuo entre a sociedade e a escola. Portanto, construir uma nova sociedade requer uma nova escola. Para tanto, Davídov (1988) adota o pressuposto de Vigotski ${ }^{3}$ (2000) de que o ensino qualificado é aquele que se adianta em relação ao desenvolvimento. Para tanto,

[...] a tarefa da escola contemporânea não consiste em dar aos alunos uma ou outra soma de fatos conhecidos, mas ensinar os alunos a orientarem-se independentemente na informação científica e em qualquer outra. Significa que a escola deve ensiná-los a pensar, isto é, desenvolver ativamente neles os fundamentos do pensamento contemporâneo mediante um ensino que impulsione o desenvolvimento mental (DAVÍDOV, 1988, p. 3 - grifo do autor).

Pesquisas que adotam o referencial Histórico-Cultural indicam que, no Brasil, desde os primeiros anos do Ensino Fundamental, os conteúdos e os métodos de ensino são predominantemente organizados a partir do método tradicional. É o que mostram: Madeira (2012); Rosa (2012); Rosa e Damazio (2012); Rosa, Damazio e Alves (2013); Hobold (2014); Lemos (2014); Mame (2014); Búrigo (2015); Silveira (2015); Crestani (2016); Freitas (2016); Galdino (2016),entre outros. Tal postura de organização do ensino obstaculiza o desenvolvimento do pensamento teórico (DAVÝDOV, 1982).

Contrapondo-se às concepções tradicionais ${ }^{4}$ de organização do ensino, Davýdov (1982) busca os fundamentos do materialismo histórico e dialético para a elaboração da sua proposta, voltada ao desenvolvimento, nos estudantes, da atividade de estudo. Seu entendimento é de que o processo de formação do ser social ocorre por meio do trabalho, gênese dos vários tipos de atividades. Dentre elas, destacamos aquelas que Leontiev (2004) chamou de "principais", por desempenhar papel essencial no processo de desenvolvimento do indivíduo humano, quais sejam: o jogo, o estudo e o próprio trabalho. A atenção, nos estudos de Davýdov, se volta à organização do ensino para que os estudantes entrem em atividade estudo. Cabe destacar que, “[...] na idade escolar inicial, as crianças realizam outros tipos de atividade, porém, a principal é a de estudo [...]” (DAVÍDOV, 1988, p. 159).

É nessa atividade que se constitui a base do pensamento teórico, isto é, as abstrações e

\footnotetext{
${ }^{3}$ As grafias Vigotski e Vigotsky se referem ao mesmo autor. Cada qual aparece no texto, conforme a obra citada.

${ }^{4}$ Davídov (1987) cosidera ensino tradicional o sistema de educação européia que se constituiu no período de surgimento do modo de produção capitalista e a ele está a serviço; até naquele momento.
} 
generalizações do tipo substancial que, segundo Davídov (1988, p. 152), “[...] encontram sua expressão no conceito teórico que serve de procedimento para deduzir os fenômenos particulares e singulares de sua base universal". No âmbito das abstrações e generalizações, Freitas (2016, p. 144), com base em Davídov, diz que “[...] a valorização delas no processo de ensino se dá pela natureza teórica, o que permite a revelação, por via do procedimento de análise, da relação geneticamente essencial de certo sistema conceitual integral".

A característica primordial da atividade de estudo está na sua constituição num sistema de ensino com conteúdo e método previamente organizados, que promove o surgimento da necessidade interna para a apropriação de determinado conhecimento com teor teórico (DAVÍDOV, 1987). Segundo Rosa (2012, p. 34), é na atividade de estudo que a criança experimenta uma necessidade interna de "apropriação real dos conhecimentos, teóricos, que também são geradores da necessidade de aprender".

Portanto, a interiorização, apropriação, dos conceitos científicos é produto do anseio pelo estudo (DAVÍDOV, 1987), que é imprescindível para o desenvolvimento do pensamento teórico, principal objetivo da atividade de estudo (DAVÍDOV, 1988). Isso significa que o lugar de desenvolvimento da generalização conceitual, em nível teórico, é na atividade de estudo, inerente à formação dos conceitos. Por consequência, "o conceito teórico se apoia na generalização teórica [...]” (NUÑES, 2009, p. 50).

A proposição davydoviana - que se centra na finalidade de colocar o estudante em atividade de estudo, voltada à apropriação do conhecimento teórico - tem sua justificativa fundamentada em reflexões e necessidades, a partir de dois contextos. Um deles como produto de seus próprios estudos referentes à história da educação. O outro decorre da análise das características dos métodos e dos conteúdos de ensino que apontavam para concepções empíricas de organização do ensino, como também de conhecimento. Em contraposição, Davýdov e colaboradores se debruçam na investigação de um modo de organização de ensino que possibilita a apropriação, por parte dos sujeitos, do que há de mais elevado na consciência social, isto é, os conhecimentos científicos (DAVÍDOV, 1988).

Em síntese, a premissa davydoviana é de que o ensino qualificado é aquele que desenvolve o pensamento teórico nos estudantes e, para tanto, requer métodos e metodologias de ensino adequados. Para que o escolar entre em atividade de estudo, Davídov (1988) propõe uma organização de ensino com a seguinte estrutura: tarefa de estudo, desenvolvida por seis ações que, por sua vez, requerem um conjunto de tarefas particulares. A tarefa de estudo é responsável pelo estímulo do pensamento dos estudantes para explicar o que desconhecem e, consequentemente, se apropriar de novos conhecimentos e procedimentos de ação 
(DAVÝDOV, 1982; DAVÍDOV, 1988). Segundo Rosa (2012, p. 55), “[...] na relação tarefa de estudo, ações e tarefas particulares está o que consideramos fundamental na sua proposição de organização do ensino".

Esse modo de organização do ensino tem por base a dialética materialista por ser “[...] o método do desenvolvimento e da explicitação dos fenômenos culturais partindo da atividade prática objetiva do homem histórico" (KOSIK; TORÍBIO, 1995, p. 39). Nessa perspectiva teórica, o entendimento é que o ser humano alcança o que há de mais evoluído por meio da apropriação dos conhecimentos científicos, acumulados historicamente.

Importa evidenciar que, na proposição davydoviana, o ponto de partida para o ensino de todos os conceitos matemáticos, na educação escolar básica, é a relação entre grandezas. Estas constituem a base para o modo de organização do sistema conceitual de adição e subtração. Isso significa dizer que a referida proposição contempla a cientificidade referente aos fundamentos da Matemática e, consequentemente, enfatiza a dimensão teórica dos conceitos. Por isso, trataremos (de forma breve) os pressupostos da teoria histórico-cultural referentes aos conceitos cotidianos e científicos e suas inter-relações com o desenvolvimento do pensamento dos escolares.

Nesse sentido, vale dizer que Davídov (1988) não despreza o conhecimento cotidiano e/ou o pensamento empírico, apenas condena sua supervalorização, por entender que obstaculiza o desenvolvimento do pensamento teórico. $\mathrm{O}$ autor explicita a seguinte diferença: “[...] o pensamento empírico cataloga, classifica os objetos e fenômenos. O teórico persegue a finalidade de reproduzir a essência do objeto estudado" (DAVÍDOV, 1982, p. 154).

A apropriação do conhecimento cotidiano, ao promover o desenvolvimento apenas do pensamento empírico, carece de superação por meio da apropriação do conceito científico (MADEIRA, 2012). A escola, ao supervalorizar os conceitos cotidianos, nega a possibilidade de inserção do estudante num processo de desenvolvimento do pensamento teórico. Isso porque, conforme Libâneo (2004, p. 27), “[...] se o ensino nutre a criança somente de conhecimentos empíricos, ela só poderá realizar ações empíricas”.

Nesse âmbito, vale mencionar que o modo de organização de ensino proposto por Davýdov “[...] enfatiza a abordagem de conceitos científicos desde o primeiro dia de escolaridade" (DAMAZIO; ROSA; SOARES, 2011, p. 3). Ao se fundamentar na Teoria Histórico-Cultural, dá ênfase ao ensino desenvolvimental, isto é, aquele que promove o desenvolvimento do pensamento teórico. No entanto, conforme Bernardes e Moura (2009, p. 477), esse tipo de ensino “[...] não se faz presente, de uma forma geral, na educação escolar em nenhum nível de escolarização na atualidade". Mas essa constatação não ocorre somente 
em relação ao contexto educacional brasileiro, pois, segundo Davídov (1987), o ensino que promove o desenvolvimento intelectual teórico não foi referência no mundo inteiro.

Realmente, ao longo de centenas de anos, a finalidade social principal da educação de massa consistiu em inculcar à maioria dos filhos dos trabalhadores somente aqueles conhecimentos e habilidades sem os quais é impossível obter uma profissão mais ou menos significativa na produção industrial e na vida social (saber escrever, contar, ler; ter ideias básicas do que se passa em seu entorno) (DAVÍDOV, 1987, p. 143).

A cultura que toma como base o conhecimento científico é um bem produzido pela humanidade, uma vez que advoga o direito de todos de se apropriarem do saber mais elaborado e atual, isto é, de teor teórico. O acesso somente ao conhecimento cotidiano, de base empírica, não é suficiente para a formação humana da atualidade. A apropriação das reais significações teóricas, isto é, que desmistifiquem aquelas dadas por relações externas, empíricas, requer uma formação humana com a premissa de que sua gênese está no processo de aprendizagem fundamentada em conceitos científicos, teóricos (VIGOTSKI, 2000; LEONTIEV, 2004; DAVÍDOV, 1988). Nesse sentido, Lemos (2014, p. 32), apoiado em Davýdov (1982), diz que “[...] a escola tem a função de gerar as condições para que os alunos se desenvolvam com base nos conceitos científicos, que elevam os níveis de pensamento para além dos modos que se constituem espontaneamente".

No entanto, o atual modelo de muitas escolas se configura com características de um ensino tradicional por promover apenas o desenvolvimento do pensamento empírico e não as abstrações e generalizações teóricas (ROSA, 2012). O conhecimento em seu nível empírico não dá a possibilidade de apropriação do essencial significado dos conceitos, bem como dos seus nexos. Libâneo e Freitas $(2013$, p. 337) chamam a atenção para a diferença entre o conhecimento empírico e o conhecimento teórico.

Diferentemente do conhecimento empírico, o conhecimento teórico não busca as semelhanças externas aparentes e comuns aos objetos em dada classe, mas revela as inter-relações e traços de objeto aparentemente isolados num todo, evidenciando seus vínculos e contradições.

Para Davýdov (1982), ao se analisar apenas os traços observáveis dos objetos, tem-se como consequência um processo de generalização e de formação do conceito científico débil. A essência dos objetos não está dada de forma imediata, pois "[...] o processo de análise permite descobrir a relação geneticamente inicial do sistema integral como sua base universal ou essência [...]" (DAVÍDOV, 1988, p. 154). É importante salientar que todo ensino promove desenvolvimento, mas a questão que se apresenta é: qual o seu conteúdo, empírico ou teórico?

Portanto, o real teor do ensino é aquele que desenvolve o ser, isto é, que usufrua daquilo que mais desenvolvido a humanidade produziu, cuja referência, na escola, é o 
conhecimento científico. A escola com teor científico, segundo Vigotski (2000), é aquela em que tanto o ensino quanto a educação se constituem em formas universais do desenvolvimento psíquico dos estudantes. Eles são os meios para a organização da atividade das crianças, de modo que elas reproduzam em si as necessidades surgidas historicamente, indispensáveis à solução com êxito das diversas tarefas da vida produtiva e cívica das pessoas.

É essa concepção e a finalidade do ensino e educação escolar, expressas por Vigotski na citação anterior, que adotam o sistema de ensino desenvolvimental. Ou seja, desenvolver o ser humano em nível das mais altas potencialidades. A elucidação de como isso ocorre em um modo de organização de ensino de Matemática, o davydoviano, é o foco de nossa investigação. Para tanto, adota como referência algumas tarefas pertinentes ao sistema conceitual constituído pela adição e subtração. A proposição davydoviana se apresenta como algo diferente em método e conteúdo (LIBÂNEO, 2004). Ela coloca o estudante em ação investigativa, na atividade de estudo, para a elaboração do pensamento conceitual com teor teórico (ROSA, 2012).

\section{Manifestações da proposição davydoviana: introdução do sistema conceitual de adição e subtração}

A seguir, faremos o estudo de três tarefas selecionadas - dentre as cinquenta e nove analisadas em nossa pesquisa mais ampla. Elas foram escolhidas por serem representativas do caminho percorrido pelo modo davydoviano de organização do ensino do referido sistema conceitual e, por consequência, para o desenvolvimento do pertinente pensamento teórico dos estudantes. Elas orientam o processo de análise referente ao movimento revelador das intenções e essências conceituais, com ênfase nos elementos de permanências, superações e surgimento, que possibilitam, aos estudantes, as devidas apropriações.

Antes, porém, vale relembrar que a universalidade do sistema conceitual de adição $e$ subtração, conforme Rosa (2012), Rosa, Damazio e Alves (2013), é a relação todo-partes. Mas no modo davydoviano de organização do ensino, conforme Gorbov, Mikulina, Savieliev (2008) e Davídov $(2012)^{5}$, ela tem sua gênese em tarefas iniciais do primeiro ano em que a preocupação central é colocar as crianças em ação investigativa referente aos diferentes tipos de grandezas e suas relações, que são base do conceito teórico de número. Isso significa dizer que, nessa perspectiva, os conceitos científicos (teórico) de adição e subtração se apresentam

\footnotetext{
${ }^{5}$ Sobrenomes desses autores em língua russa Горбов, Микулина, Савельева (2008) е Давыдов (2012).
} 
no âmbito do conceito de número como relações entre grandezas que se expressam na especificidade todo-partes. Em síntese, os estudos apontados até o momento - entre outros: Rosa (2012); Crestani (2016); Rosa, Damazio, Alves (2013); Búrigo (2015) - nos dão subsídios para que, no processo de análise, possamos admitir que, até então, as muitas tarefas particulares no âmbito de seis ações ${ }^{6}$ de estudos - do modo davydoviano de organização do ensino - imprimiram um movimento conceitual. Salientamos que a adição e a subtração se inserem no contexto do conceito de número, entendido como relação entre grandezas. Esquematicamente:

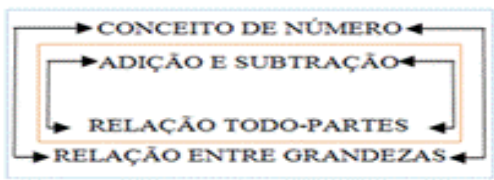

Figura 1 - Esquema caracterizador das operações da adição e subtração no contexto do conceito de número Fonte: Produção nossa, com base em Gorbov, Mikulina, Savieliev (2008) e Davídovet al. (2012).

Nesse âmbito, o movimento pertinente ao desenvolvimento do pensamento conceitual de adição e subtração, em sua tarefa introdutória (Figura1), traz um componente conceitual que preanuncia a relação essencial todo-partes. Sobre uma mesa da sala de aula, estão dois recipientes iguais, com volumes de líquido diferentes (Interpretação nossa, a partir da tradução de Elvira Kim, de GORBOV, MIKULINA, SAVIELIEV, 2008).

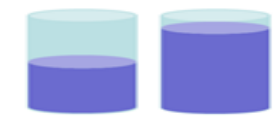

Figura 2 - Determinação da diferença

Fonte: Produção com base em Gorbov, Mikulina, Savieliev (2008).

As crianças estabelecem a relação entre os volumes de líquido dos dois recipientes e concluem que o segundo é maior que o primeiro. O professor solicita que registrem no caderno a diferença de volume, por meio de segmentos de reta ${ }^{7}$, enquanto ele faz a mesma representação no quadro (GORBOV, MIKULINA, SAVIELIEV, 2008). Esse tipo de registro (Figura2) é denominado por Davýdov (1982) de representação gráfica ${ }^{8}$ (por segmento de retas).

\footnotetext{
${ }^{6}$ Davídov (1988), em seu modo de organização do ensino de Matemática, estabelece seis ações de estudo: 1) Transformação dos dados da tarefa a fim de revelar a relação universal, geral, do objeto estudado; 2) Modelação da relação universal na unidade das formas literal, gráfica e objetal; 3) Transformação do modelo da relação universal para estudar suas propriedades em forma pura; 4) Dedução e construção de um sistema de tarefas particulares, resolvidas por um procedimento geral; 5) Controle da realização das ações; 6) Avaliação da apropriação do procedimento geral como resultado da solução da tarefa de estudo.

${ }^{7} \mathrm{O}$ conceito de linha reta e segmentos de reta já foi introduzido e desenvolvido em tarefas anteriores que tratavam das grandezas. É neste momento que as crianças aprendem novas figuras geométricas, como linha, linha reta, ponto e segmento de reta.

${ }^{8}$ No sistema davydoviano, as crianças se envolvem em três tipos de representação: objetal, gráfica e literal.
} 


\section{Figura 3 - Representação gráfica da ação objetal}

Fonte: Produção com base em Gorbov, Mikulina, Savieliev (2008).

Com o registro no quadro, o professor explica que o objetivo da tarefa é igualar os volumes dos recipientes. Para tanto, estabelece uma condição: o recipiente com menor volume precisa ter a mesma quantidade de líquido que o outro 9 .

Ele questiona: O que precisamos fazer para cumprir a condição estabelecida? Esperase que as crianças respondam: Temos que colocar líquido no primeiro recipiente. Se assim for, o professor atende à sugestão das crianças, porém, coloca no recipiente a quantidade de água que, visivelmente, não é suficiente. Essa ação requer das crianças atenção à manipulação para que as alertem da necessidade de colocar mais líquido. Então o professor solicita que elas de em uma orientação mais apropriada, isto é, que expliquem qual é exatamente a quantidade que falta, a diferença. Finalmente, ele iguala o volume de água e sugere que façam o mesmo com os segmentos registrados nos cadernos (Figura3). Elas completam com outra cor o segmento menor, de tal modo que fique igual ao comprimento do segmento maior (GORBOV, MIKULINA, SAVIELIEV, 2008).
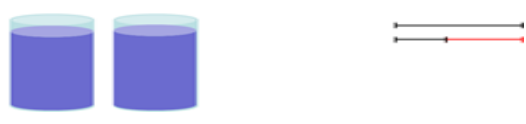

Figura 4 - Igualar os volumes

Fonte: Produção com base em Gorbov, Mikulina, Savieliev (2008).

Realizada a alteração no segmento de reta menor, a fim de se igualar ao segmento maior, o professor sintetiza a tarefa com alguns questionamentos. 1) Vocês fizeram a mesma manipulação que eu? Espera-se que as crianças respondam afirmativamente 2) Eu coloquei líquido,e vocês? Suponha-se que respondam: Não colocamos líquido, mas completamos o desenho. 3) Como, então, poderemos chamar a nossa ação? O diálogo orientador dará as condições para que as crianças concluam: Assim como o professor, também aumentamos; ou, ainda, completamos a diferença (GORBOV, MIKULINA, SAVIELIEV, 2008).

A primeira tarefa trata de elementos conceituais, tais como: a medição, o aspecto quantitativo (aumentar o volume) e a representação do resultado da medição. Os direcionamentos do professor colocam o pensamento das crianças em movimento, na busca da explicitação da relação universal todo-partes, peculiar ao conceito teórico de adição e subtração. Isso ocorre pelo trânsito dos estudantes por dois tipos de representações: objetal

\footnotetext{
${ }^{9}$ Sugestão: Esta tarefa pode ser dada na forma de uma história, por exemplo, ligada à composição de uma poção, etc.
} 
(recipientes e líquido) e gráfica (segmentos). Haveria duas possibilidades de solução: aumentar e diminuir o volume de líquido de um ou de outro recipiente e do respectivo segmento. Porém, a tarefa direciona para a ideia de aumentar. No entanto, isso só é possível com a presença do outro recipiente e do segmento, que possibilitam a comparação.

Nesse âmbito, implicitamente, configura-se outra ideia central do sistema conceitual em foco que é a relação de igualdade e desigualdade. Ora, se é preciso aumentar, significa que se está diante de uma desigualdade que, conceitualmente, demanda um movimento que leve à igualdade, o que requer uma referência, no caso, o recipiente com maior volume. Nessa circunstância de aumento, configura-se o prenúncio de outra ideia caracterizadora do sistema conceitual: se há uma parte, é necessário o acréscimo de outra para atingir o todo. Gorbov, Mikulina, Savieliev (2008) dizem que, nessas duas representações, há uma ideia peculiar ao sistema conceitual: determinar a diferença. Tem-se uma parte conhecida, referência que cria a necessidade de identificação da outra, o que ocorre com a determinação da diferença.

Observa-se que a primeira tarefa traz ideias e abstrações com um teor anunciativo, pois elas se apresentam no contexto da primeira ação de estudo ${ }^{10}$ do modo davydoviano de organização de ensino. A atenção não está somente para a manipulação dos objetos, mas no movimento que incita o surgimento de elementos conceituais que se configurarão na representação gráfica que a situação propõe ${ }^{11}$.

Isso ocorre na relação entre dois segmentos de retas, em que um deles (o mais curto) precisa ser aumentado até se igualar ${ }^{12}$ ao de maior comprimento, concomitantemente, à ação objetal de acrescentar líquido no recipiente. Assim sendo, a relação todo-partes se inicia no âmbito conceitual das abstrações de igualdade e desigualdade, representado por duas grandezas distintas: a objetal, que tratou do volume, e a gráfica (representação geométrica), reveladora da grandeza comprimento.

Esses elementos se apresentaram em tarefas anteriores, dentre outros, a manipulação de objetos e a construção dos segmentos de retas, em atendimento à finalidade de formação do pensamento teórico de número, atrelado à relação entre grandezas no processo de medição. Em outros termos, é esse o contexto de introdução dos conceitos de adição e subtração, bem como suas relações internas sobre equação e resolução de problemas. Ao se ter como referência uma situação objetal, atende-se a uma das “[...] teses fundamentais da teoria

\footnotetext{
${ }^{10}$ Transformação dos dados da tarefa, a fim de revelar a relação universal do objeto de estudo.

11 Outras tarefas referentes às relações de igualdade e desigualdade foram desenvolvidas anteriormente para introduzir a representação gráfica.

12 Para Caraça (1951, p. 53), “[...] um segmento de reta é uma grandeza geométrica”.
} 
materialista dialética do pensamento [...]”, conforme defende Davýdov (1982, p. 278).

Enfim, a primeira tarefa da proposição davydoviana que introduz o conceito de adição e subtração, ao prenunciar a relação todo-partes, traz dois componentes essenciais: 1) a ideia comparativa entre duas grandezas pertinente à adição; 2) uma representação objetal e outra gráfica, sem ainda se apresentar a necessidade de expressar o valor numérico. Isso significa que a relação universal do referido sistema conceitual não traz explicitamente uma significação aritmética. Em vez disso, revela-se a inter-relação entre o plano objetal e o geométrico.

A ação que motiva o desenvolvimento dessa tarefa é caracterizada pelo seguinte esquema:

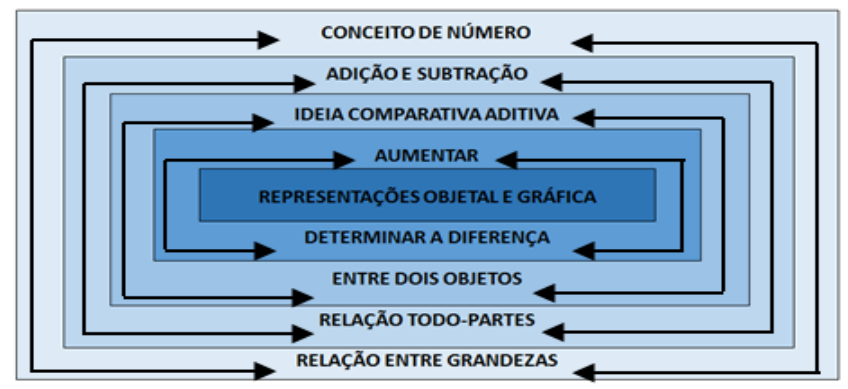

Figura 5 - Ação motivadora do desenvolvimento da tarefa em análise

Fonte: Produção nossa, com base em Gorbov, Mikulina, Savieliev (2008) e Davídov et al. (2012).

A segunda tarefa é semelhante à anterior, pois são colocados diante dos estudantes dois recipientes de formatos iguais e com volumes de líquidos diferentes. Dessa vez, a condição estabelecida é igualar o volume de líquido maior com o de volume menor, com o objetivo de representá-los por meio de segmentos de reta (Interpretação nossa, a partir da tradução de Elvira Kim, de GORBOV, MIKULINA e SAVIELIEV, 2008).

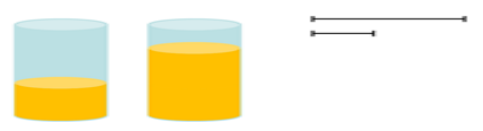

Figura 6 - Igualar os volumes

Fonte: Produção com base em Gorbov, Mikulina, Savieliev (2008).

Verifica-se que os estudantes se envolvem em operações da ação de retirar líquido do volume maior, diferentemente do que ocorreu na tarefa anterior, que requeria o aumento. Isso significa que, implicitamente, há uma outra condição própria da operação da subtração, ou seja, eliminar a diferença. Com a construção dos dois segmentos (Figura5), torna-se possível a demonstração de movimento necessário para igualar as quantidades. Para tanto, são feitos riscos em uma parte do segmento maior (Figura6), que simula a sua diminuição (ГОРБОВ; МИКУЛИНА; САВЕЛЬЕВА, 2008). 


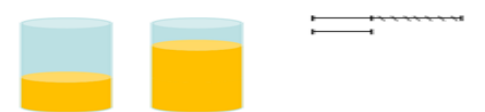

Figura 7 - Representação gráfica a partir da ação objetal Fonte: Produção com base em Gorbov, Mikulina, Savieliev (2008).

Subjacente à ação realizada, também está a relação todo-partes. O ponto de partida é o volume maior (todo) e o ponto de chegada, o volume menor (uma parte). O mesmo ocorre no que diz respeito ao comprimento dos segmentos de reta, em que a parte cortada em um deles é destacada por meio de "riscos". Tal movimento, "retirar líquido" e "riscar o segmento", traz a ideia peculiar da operação subtrativa que, segundo Gorbov, Mikulina, Savieliev (2008), é eliminar ${ }^{13}$ a diferença.

Portanto, difere da tarefa anterior, pois contempla a ideia aditiva que consiste em determinar a diferença. Nesse sentido, Davídov (1988, p. 176) diz que "[...] a lei geral de interiorização, a forma inicial das ações de estudo é seu cumprimento desdobrado em objetos exteriormente representados". A ação objetal está fortemente presente nas tarefas davydovianas, pois constitui a base para desenvolver capacidades psíquicas como: reflexão e análise. Consequentemente, para o desenvolvimento da consciência e do pensamento teórico.

$\mathrm{Na}$ referida tarefa, os elementos que permaneceram em relação à anterior foram: a ação objetal e gráfica para as respectivas grandezas, volume e comprimento, sem qualquer presença do valor numérico. Cabe ressaltar que, embora as tarefas apresentadas contemplem somente grandezas contínuas, a proposição davydoviana também trata de situações com grandezas discretas (com o mesmo teor teórico das demais grandezas); por exemplo, a relação de igualdade e desigualdade entre objetos distintos. A ação que motiva o desenvolvimento da segunda tarefa é caracterizada no seguinte esquema:

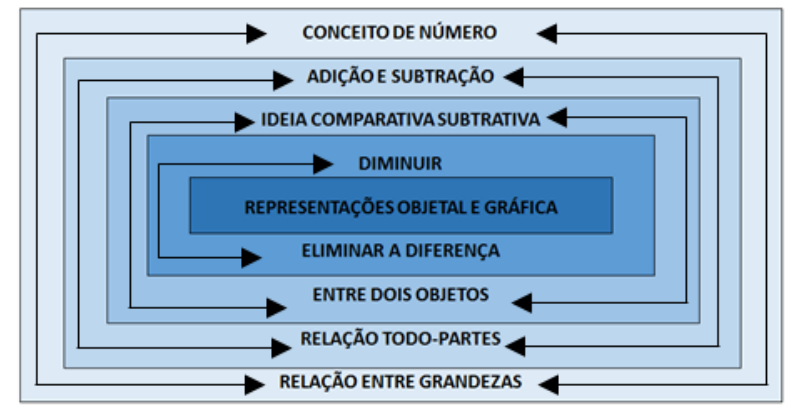

Figura 8 - Ação motivadora da segunda tarefa em análise

Fonte: Produção nossa, com base em Gorbov, Mikulina, Savieliev (2008) e Davídovet al. (2012).

As duas tarefas introduzem as relações internas dos conceitos de adição e subtração e, por extensão, a iminência de ideias referentes à equação, meio essencial de resolução de

\footnotetext{
${ }^{13}$ Os grifos nas palavras determinar e eliminar são dos próprios autores.
} 
problemas. A ideia inicial de "acrescentar líquido" e aumentar um dos segmentos se vincula à necessidade de determinar a diferença, isto é, a outra parte do todo que constitui em uma propriedade da adição. Assim, também "tirar líquido" e "riscar segmento" se caracterizam em especificidade da subtração, que requer a eliminação da diferença.

Portanto, a diferença se refere tanto à adição (determiná-la) quanto à subtração (eliminá-la). É ela que gera o movimento caracterizador da relação de igualdade e desigualdade que, na proposição davydoviana, proclama a relação essencial todo-partes. Caso fossem iguais, ter-se-ia o todo sem a necessidade de especificar as suas respectivas partes; consequentemente, não haveria qualquer relação pertinente ao sistema conceitual. Em outras palavras, a diferença permite o aumento ou a diminuição em relação ao todo.

A terceira tarefa compõe-se de duas situações. A primeira estabelece que, sobre a mesa do professor, está um recipiente não cheio de líquido (Figura 8). As crianças desenham no caderno o segmento que representa o volume de líquido (Interpretação nossa, a partir da tradução de Elvira Kim, de GORBOV, MIKULINA, SAVIELIEV, 2008).

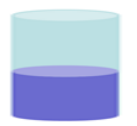

Figura 9 - Ação objetal e representação gráfica inter-relacionadas Fonte: Produção com base em Gorbov, Mikulina, Savieliev (2008).

Feito o registro, o professor coloca mais líquido no recipiente e sugere às crianças que representem esse procedimento no segmento de reta construído (Figura 9). Como o volume aumentou, então é conveniente aumentar o comprimento do segmento (GORBOV, MIKULINA, SAVIELIEV, 2008).

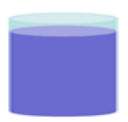

Figura 10 - Acrescentar o volume, consequentemente, aumentar o segmento de reta Fonte: Produção nossa, com base em Gorbov, Mikulina, Savieliev (2008).

Numa segunda situação, o professor mostra uma tira vermelha de papel ${ }^{14}$, que também é distribuída para cada criança (Figura 10). No quadro, desenha um segmento de reta que representa o comprimento da tira apresentada (GORBOV, MIKULINA, SAVIELIEV, 2008).

Figura 11 - Estabelecer relação com a superfície de área e com o segmento de reta Fonte: Produção nossa com base em Gorbov, Mikulina, Savieliev (2008).

\footnotetext{
${ }^{14}$ A proposição davydoviana introduz as tiras de papel nas primeiras tarefas, anteriores a essas duas em processo de análise, com o objetivo de estabelecer relações e, consequentemente, ser o ponto de partida para a compreensão teórica do conceito de grandeza.
} 
A próxima ação do professor é riscar uma parte do segmento construído. Então sugere que as crianças façam o mesmo com as suas respectivas tiras (Figura 11). Para elas, a nova representação gráfica indica a necessidade de diminuir o comprimento da tira, isto é, corta-se uma parte (GORBOV, MIKULINA, SAVIELIEV, 2008).

Figura 12: Realizaçãoda mesma ação em grandezas diferentes Fonte: Produção nossa com base em Gorbov, Mikulina, Savieliev (2008).

Essa terceira tarefa traz como peculiaridade externa a proposição de duas situações como forma de mostrar que as relações objetais não ocorrem somente com o envolvimento de um mesmo tipo de grandeza. Por isso, na primeira situação, explicita-se a grandeza volume e, na segunda, o comprimento da largura da tira de papel.

Outra particularidade da tarefa diz respeito às operações a serem desenvolvidas, pois, diferentemente do que ocorre nas anteriores, professor e estudantes têm incumbências distintas: modificação no objeto ou na representação gráfica. $\mathrm{Na}$ primeira situação, o professor faz a modificação no volume do recipiente, enquanto o procedimento dos alunos ocorre no segmento. Na segunda, invertem-se as incumbências: o professor altera o desenho e as crianças, a tira de papel.

Mas, em ambas as situações a característica interna (conceitual) que se distingue das duas tarefas anteriores é que o despontar da relação universal (todo-partes) não se apresenta na comparação entre duas grandezas a partir de dois objetos. Nesse momento, o manuseio e as transformações do volume e do comprimento em questão se dão, respectivamente, no recipiente e na tira. Consequentemente, a representação gráfica se dá por um único segmento de reta, que é um implemento da base do modelo representativo a ser sistematizado em estágios superiores.

Em síntese, a ação que motiva o desenvolvimento da terceira tarefa é caracterizada no seguinte esquema:

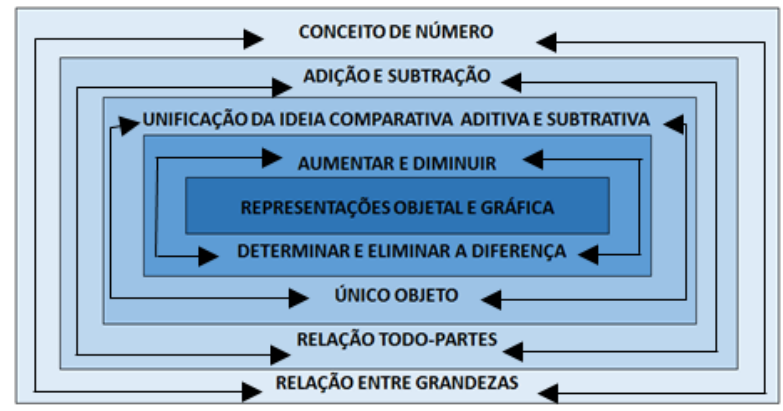

Figura 13 - Ação motivadora da terceira tarefa em análise

Fonte: Produção nossa, com base em Gorbov, Mikulina, Savieliev (2008) e Davídovet al. (2012). 
Importa destacar que esse movimento tem por base o pressuposto de Davídov (1988, p. 137) de que "[...] o surgimento do experimento sensório-objetal constituiu, por essência, o surgimento do pensamento teórico em sua forma externa, objetal". Nesse sentido, importa dizer que as três tarefas analisadas no decorrer deste estudo apresentam um movimento em comum: parte da manipulação de objetos (representação objetal) e desenvolve a representação gráfica.

\section{Considerações}

Resta-nos, neste espaço, a explicitação de nossas reflexões das sínteses realizadas a respeito das três tarefas do primeiro ano escolar do modo davydoviano de organização do ensino, que refletem o movimento introdutório da pesquisa mais ampla produzida pelos autores. Consequentemente, revelam as intenções e essências conceituais, com ênfase nas suas permanências, superações e surgimento referente ao sistema conceitual de adição e subtração no âmbito de sua universalidade, relação todo-partes, com base no conceito de número na relação entre grandezas.

Para alcançar a apropriação dos conceitos científicos, Davídov (1988) se preocupou em elaborar uma organização de ensino, cuja finalidade é propiciar nos estudantes o desenvolvimento do pensamento teórico, mediado por abstrações e generalizações do objeto em análise. Inerentes ao pensamento teórico estão as peculiaridades das abstrações e generalizações teóricas formadas com fundamentos dos conceitos científicos (DAVÍDOV, 1988), o que requer método e conteúdo previamente organizados.

Consequentemente, o processo que conduz ao pensamento teórico conclama pela busca de manifestações decorrentes das relações da essência constituinte do objeto, o que demanda a análise dos aspectos sensoriais perceptíveis. Como resultado, implica na apreensão do objeto em sua totalidade, isto é, em unidade. Em outras palavras, trata-se de compreender todas as contradições internas subjacentes ao objeto (KOPNIN, 1978). Portanto, atingir o conhecimento da essência significa compreender o objeto em sua forma mais desenvolvida. Ou seja, isso se dá pelas mediações, o que requer um processo de análise, por meio de abstrações e generalizações (KOPNIN, 1978).

Com base nesse movimento, expusemos as elaborações que promovem as três primeiras tarefas particulares do sistema de conceito (adição e subtração) referente ao primeiro ano escolar. Para tanto, debruçamo-nos sobre o objetivo específico de analisar os elementos novos que cada uma delas trazem, principalmente,no que diz respeito ao papel da 
relação entre grandezas no referido sistema conceitual, bem como as peculiaridades de cada um dos conceitos constituintes do sistema em estudo, além das características do teor do pensamento teórico referente a cada conceito do sistema referência do presente estudo. Nesse âmbito, centramos esforços na análise do movimento de permanência e de surgimento de características do sistema de conceito - adição e subtração - articulado com o modo peculiar de organização de cada tarefa.

A análise das três tarefas- com base na teoria materialista histórica e dialética - dá indícios de que elas imprimem, nos estudantes, o movimento do pensamento de redução do concreto ao abstrato pertinente ao sistema de conceito.Tal movimento se fundamenta nos componentes que permanecem em todas as tarefas: na universalidade da relação essencial todo-partes, mas que se insere no âmbito do conceito teórico de número, cuja base genética inicial é relação entre grandezas (DAVÝDOV, 1982).

Mas, cada uma delas também traz uma nova característica que imprime um movimento ascendente de pensamento. Isso se explicita quando na primeira tarefa se apresenta a ideia comparativa aditiva que consiste em determinar a diferença entre dois objetos, por meio de representações objetal e gráfica (segmento de reta). A segunda tarefa, como novo componente, conceitua a ideia comparativa subtrativa que consiste em eliminar a diferença entre dois objetos, por meio das referidas representações. A terceira tarefa se distingue das demais pela unificação da ideia comparativa aditiva e subtrativa num único objeto, por meio das duas mencionadas representações.

Contudo, essas tarefas - por se constituírem com teor teórico pertinente à primeira (dentre as seis) ação de estudo do modo davydoviano de organização do ensino - ainda não têm o potencial para colocar os estudantes em movimento de pensamento conceitual de ascensão do abstrato ao concreto, conforme entendimento da matriz teórica, o materialismo histórico e dialético. Isso só ocorrerá, conforme Freitas (2016), com tarefas da segunda a sexta ações de estudo. Ou seja, no processo que se estende a partir de tarefas similares àquelas aqui em estudo, que apenas vislumbram as primeiras abstrações como, por exemplo,igualdade $e$ desigualdade, surgidas no processo de relação entre grandeza.

Observa-se, ainda, que as tarefas não seguem um movimento linear, mas de ida e volta. A apreensão de um componente ou ideia peculiar à adição e subtração ocorre numa inter-relação em que, necessariamente, um precisa de outro. O movimento de ida prescinde do movimento de volta, cujo componente gerador é a desigualdade que cria necessidade de determiná-la ou eliminá-la. Estas se constituem em propriedades, respectivamente, da adição e subtração. Por exemplo, "determinar ou tirar líquido" e "aumentar ou riscar segmento" se 
caracterizam em especificidades conceituais do sistema adição/subtração. Portanto, a diferença gera o movimento caracterizador da relação de igualdade e desigualdade que proclama pela relação essencial todo-partes, geral, dos referidos conceitos.

Nesse âmbito, as primeiras apropriações do conceito são anunciativas das interrelações das significações algébrica, aritmética e geométrica. Algébrica, porque há caráter de generalização, em vez de apenas um teor particular, por exemplo de quantificação. Aritmética, por anunciar a possibilidade de contagem. Geométrica, que se manifesta desde o tratamento das grandezas (comprimento, área e volume) até a representação por segmento de reta.

Vale salientar que nossa preocupação, no processo de análise, foi com o detalhamento de cada uma das tarefas, entendidas como aquelas que traduzem os diversos componentes e ideias caracterizadoras do sistema conceitual de adição e subtração. No entanto, não significa que no processo de ensino essa pormenorização seja evidenciada, pois entendemos que o conteúdo das tarefas em si e o entrelaçamento entre elas fazem com que as crianças se apropriem e infiram muitos elementos trazidos à tona ou não em cada uma delas.

Mesmo se tratando de tarefas introdutórias, a análise nos permitiu a apreensão de que a apropriação teórica, pelos estudantes, do conceito de adição e subtração ocorre num trânsito entre as relações das diversas grandezas: discretas e contínuas (comprimento, área, volume, massa). Isso significa que não se adiciona ou se subtrai objetos em si, mas números que representam determinadas unidades oriundas de um processo de medição. Por exemplo, encher ou esvaziar um recipiente com água é comum à maioria das crianças. Essa situação, na proposta davydoviana, recebe um componente científico que é a grandeza volume no processo de medição, de aumento e de diminuição.

Diríamos, então, que as tarefas nascem complexas, porque recebem formas de conceitos científicos e assim permanecem, pois continuam a incluir novos componentes conceituais. Mas essas complexidades não ficam estagnadas, pois as tarefas trazem um teor questionador que coloca o pensamento dos estudantes em movimento de pensamento, em ação investigativa, como diz Davídov (1988).

Sendo assim, tais complexidades das tarefas são da convivência da criança em atividade de estudo. E, como tal, criam necessidades que despertam para novas possibilidades. Caso assim não fosse, a criança continuaria em estado de desenvolvimento em nível de conceitos espontâneos (VIGOTSKI, 2000), isto é, não estaria em processo formativo, próprio da atividade de estudo (DAVÍDOV, 1988). Desse modo, a adição e subtração se confluem em um sistema - que em tarefas não analisadas nesse artigo - incidirá na inclusão do conceito de equação, base para a resolução de problemas, em um movimento dialético impulsionado pela 
relação todo-partes, num contexto de relação entre grandezas e da concepção de número real.

\section{Agradecimentos}

À FAPESC (Fundação de Amparo à Pesquisa e Inovação do Estado de Santa Catarina) e ao CNPq (Conselho Nacional de Desenvolvimento Científico e Tecnológico), pelo apoio financeiro concedido para a realização desta pesquisa.

\section{Referências}

BERNARDES, M. E. M.; MOURA, M. O. de. Mediações simbólicas na atividade pedagógica. Educação e Pesquisa (USP. Impresso), v. 35, p. 463-478, 2009.

BÚRIGO, L. S. M. Necessidades Emergentes na Organização do Ensino Davydoviano para o Número Negativo.2015. 153 f. Dissertação (Mestrado em Educação) - Universidade do Extremo Sul Catarinense, Criciúma, 2015.

CARAÇA, B. J. Conceitos Fundamentais da Matemática. Lisboa: Sá da Costa, 1951.

CRESTANI, S. Organização do Ensino de Matemática na Perspectiva do Desenvolvimento do Pensamento Teórico: uma reflexão a partir do conceito de divisão. 2016. 125f. Dissertação (Mestrado em Educação) - Universidade do Sul de Santa Catarina, Tubarão, 2016.

DAMAZIO, A.; ROSA, J. E.; SOARES, M. T. Conceito de Número no Sistema de Ensino de Davydov. In: CONFERÊNCIA INTERAMERICANA DE EDUCAÇÃO MATEMÁTICA, 13., 2011, Recife. Anais... Recife: Universidade Federal de Pernambuco, 2011. p. 1-11.

DAVÍDOV, V. V. Análisis de los Principios Didácticos de la Escuela Tradicional y Posibles Principios de Enseñanza en el Futuro Próximo. In: SHUARE, M. (Comp.). La psicología Evolutiva y Pedagógica en la URSS.Moscú: Progreso, 1987. p. 143-155.

. La Enseñanza Escolar y el Desarrollo Psíquico:investigación teórica y experimental. Trad. Marta Shuare. Moscú: Editorial Progreso, 1988.

DAVÍDOV, V. V.; SLOBÓDCHIKOV, V. I. La Enseñanza que Desarrolla en la Escuela del Desarrollo. In: La educación y la enseñanza: una mirada al futuro. Moscú: Progreso, 1991.p. 118-144.

DAVÝDOV, V.V. Tipos de Generalización en la Enseñanza.3. ed. Habana: Editorial Pueblo y Educación, 1982.

. La Renovación de la Educación y el Desarrollo Mental de los Alumnos. Revista de Pedagogía, Santiago, n. 403, p. 197-199, jun. 1998.

FIORENTINI, D. Alguns Modos de Ver e Conceber o Ensino da Matemática no Brasil. Zetetiké, Campinas, Unicamp, Ano 3, n. 4, p. 1-37, 1995.

FREITAS, D. O Movimento do Pensamento Expresso nas Tarefas Particulares Proposta por Davýdov e Colaboradores para Apropriação do Sistema Conceitual de Fração. 2016.167 f. Dissertação (Mestrado em Educação) - Universidade do Extremo Sul Catarinense, Criciúma, 2016. 
GALDINO, A. P. S. O Conhecimento Matemático de Estudantes do $3^{\circ}$ ano do Ensino

Fundamental sobre o Conceito de Multiplicação: um estudo com base na teoria Histórico-Cultural. 2016. 110 f. Dissertação (Mestrado em Educação) - Universidade do Sul de Santa Catarina, Tubarão, 2016.

HOBOLD, E. S. F. Proposições para o Ensino da Tabuada com Base nas Lógicas Formal e Dialética.2014. 199 f. Dissertação (Mestrado em Educação) - Universidade do Sul de Santa Catarina, Tubarão, 2014.

KOPNIN, P. V.A Dialética como Lógica e Teoria do Conhecimento. Tradução de Paulo Bezerra. Rio de Janeiro: Civilização Brasileira, 1978.

KOSIK, K.; TORÍBIO, A. Dialética do Concreto.2. ed. Rio de Janeiro: Paz e Terra, 1995.

LEMOS, L. V. A Atividade do Professor e a Matemática no Ensino Fundamental:uma análise sócio-histórica de sua estrutura e conteúdo. 2014. 154 f. Dissertação (Mestrado em Educação) Universidade do Extremo Sul Catarinense, Criciúma, 2014.

LEONTIEV, A. N. Actividad, consciência, personalidade. 2. ed. Havana: Pueblo y Educacion, 1983. O Desenvolvimento do Psiquismo. 2. ed. São Paulo: Centauro, 2004.

LIBÂNEO, J. C. A Didática e a Aprendizagem do Pensar e do Aprender: a Teoria Histórico-Cultural da atividade e a contribuição de Vasili Davydov. Revista Brasileira de Educação, Rio de Janeiro, n. 27, p. 5-24, 2004.

LIBÂNEO, J. C.; FREITAS, R. A. M. M. Vasily Vasilyevich Davydov: a escola e a formação do pensamento teórico-científico. In: LONGAREZI, A. M.; PUENTES, R. V. (Org.).Ensino desenvolvimental:vida, pensamento e obra dos principais representantes russos. Uberlândia: EDUFU, 2013. p. 315-350.

LURIA, A. R. Desenvolvimento Cognitivo. Tradução de Fernando Limongeli Gurgueira. São Paulo: Ícone, 1990.

MADEIRA, S. "Prática":uma leitura histórico-crítica e proposições davydovianas para o conceito de multiplicação.2012.168 f.Dissertação (Mestrado em Educação) - Universidade do Extremo Sul Catarinense, Criciúma, 2012.

MAME, O. A. C. Os Conceitos Geométricos nos Dois Anos Iniciais do Ensino Fundamental na Proposição de Davýdov. 2015. 160 f. Dissertação (Mestrado em Educação) - Universidade do Extremo Sul Catarinense, Criciúma, 2014.

NUÑES, B. I. Vygotsky, Leontiev e Galperin:formação de conceitos e princípios didáticos. Brasília: Líber Livro, 2009.

ROSA, J. E. da.Proposições de Davydovy para o Ensino de Matemática no Primeiro Ano Escolar:inter-relações dos sistemas de significações numéricas.2012.244f.Tese (Doutorado em Educação) - Universidade Federal do Paraná, Curitiba, 2012.

. O Ensino de Matemática. In: SCHLICKMANN, Maria Sirlene Pereira (Org.). Áreas do Conhecimento: Diálogos em articulação. Palhoça: Editora da Unisul Virtual, 2016. p. 184 - 202.

ROSA, J. E.; DAMAZIO, A. O ensino do conceito de número: uma leitura com base em Davydov. Revista Unión,San Cristobal de La Laguna, v. 30, p. 81-100, 2012. 
ROSA, J. E.; DAMAZIO, A.; ALVES, E. S. B. Adição e subtração em Davydov. Boletim GEPEM/Grupo de Estudos e Pesquisas em Educação Matemática, Rio de Janeiro, n. 63, p. 61-75, jul./dez. 2013.

ROSENTAL, M. Da Teoria Marxista do Conhecimento. Rio de Janeiro: Editorial Vitória, 1956.

ROSENTAL, M. M. Princípios de Logica Dialectica.Tradução de Augusto Vidal Boget. Uruguai: Montevideo, 1962.

SILVEIRA, G. M. Unidade entre Lógico e Histórico no Movimento Conceitual do Sistema de Numeração Proposta por Davýdov e Colaboradores para o Ensino das Operações da Adição e Subtração. 2015.188f.Dissertação (Mestrado em Educação) Universidade do Sul de Santa Catarina, Tubarão, 2015.

SOUZA, M. B. O Ensino do Conceito de Número: objetivações nas proposições davydovianas e formalista moderna. 2013. 237 f. Dissertação (Mestrado em Educação) - Universidade do Extremo Sul Catarinense, Criciúma, 2013.

TRIVIÑOS, A. N. S. Introdução à Pesquisa em Ciências Sociais: a pesquisa qualitativa em educação. São Paulo: Atlas, 1995.

VIGOTSKI, L. S. A Construção do Pensamento e da Linguagem. Tradução de Paulo Bezerra. São Paulo: Martins Fontes, 2000.

ГОРБОВ С. Ф.; МИКУЛИНА Г. Г.; САВЕЛЬЕВА О. В. Обучение математике. 1 класс: Пособие для учителей начальной школы(Система Д.Б. Эльконина - В.В. Давыдова). 2-е ида, перераб. - М.:ВИТА-ПРЕССб 2008. 128p. [GORBOV, S.F.; MIKULINA, G.G.; SAVIELIEV, O.V. Ensino de Matemática. 1 ano: livro do professor do ensino fundamental(Sistema do D.B. Elkonin V.V. Davidov). 2.ed. Moscou: Vita-Press, 2008.]

ДАВЫДОВ, В. В. О. et al. Математика, 1-Kjiacc.Mockba: Mnpoc - Аргус, 2012a. Davídov, V.V. Matemática, $\mathbf{1}^{\mathbf{a}}$ série. Livro didático e de exercícios para os estudantes da primeira série. Moscou: MIROS, Argus, 2012.

Submetido em 23 de Janeiro de 2018. Aprovado em 14 de Novembro de 2018. 